\title{
Integration of Autograph in Improving Mathematical Problem Solving and Mathematical Connection Ability Using Cooperative Learning Think-Pair-Share
}

\author{
Ida Karnasih \\ Universitas Negeri Medan, Indonesia \\ <ikarnasih2001@yahoo.com> \\ Mariati Sinaga \\ <mariatisinaga@yahoo.com>
}

\begin{abstract}
The aim of this study was to investigate students' mathematical problem solving and mathematical connection ability in cooperative learning setting using Dynamic Software Autograph. This experimental study was conducted at high school in learning statistics. The collection of the data was done using observation sheets, documentation, attitude scale, and performance tests. Repeated measure tests were delivered to students for four times. The result of the analysis showed that: (1) Using Dynamic Software Autograph in teaching learning statistics with cooperative learning Think-Pair-Share improved students' problem solving and mathematical connection ability; (2) Students' activity during teaching learning processes continuously improved; (3) The result of analysis of the questionnaire showed that most students like learning statistics using cooperative learning with dynamic software Autograph; (4) Students were very active and showed positive attitude toward learning using cooperative learning Think-Pair-Share using dynamic software Autograph.
\end{abstract}

Keywords: Dynamic Software Autograph, Cooperative Learning, Mathematical Problem Solving, Mathematical connection.

\section{Introduction}

The rapid advancement of sciences and technology has brought about many changes, challenges, and competitiveness in how people learn and adapt themselves to the process of teaching and learning. Numerous studies have shown the positive impact of integrating technological tools in the teaching and learning process of mathematics in the classroom. But, in reality, there are numerous problems encountered in its implementation in the classroom. To overcome these problems, mathematics educators should keep up with these teaching challenges by preparing not only themselves but also their students in order to improve their competitiveness. In this era of information and technology, they need to prepare, understand, and apply their knowledge and skills in their workplace.

One important technological tool is the computer and there are numerous potential benefits for using the computer as a tool for instruction in an educational setting. Firstly, technological tools such as the computer help to support cognitive processes by reducing the memory load of a student and by encouraging awareness of the problem-solving process. Secondly, tools such as the computer can share the cognitive load by reducing the time that 
students spend on computation. Thirdly, the tools allow students to engage in mathematics that would otherwise be out of their reach, thereby stretching students' opportunities. Fourthly, tools can support logical reasoning and hypothesis testing by allowing students to test conjectures easily (Kurz, Midleton \& Yanik, 2005). Instructionally, computers allow for a record of problem-solving processes to be constructed and replayed as a window into children's thinking. Computer also offer interactive learning for promoting students' high order thinking skills and for showing them the role of Mathematics in interdisciplinary settings and the value of these connections. Technology can indeed change the way classrooms operate, integrating multimedia during learning, and online accessibility and thus making teaching and learning more interactive and participatory (Martin, 2006).

In Indonesian educational practices, the use of technology is still in the initial stage. Although data on the actual use of technology in schools have never been comprehensively surveyed, the use of computer is primarily for administrative purposes. It has not yet been widely implemented as an integral part of the teaching and learning of mathematics in schools. The teaching-learning process is still dominated by conventional teaching that places emphases upon practice in manipulating expressions and algorithms as a precursor to solving problems.

Indonesia's newspaper have extensively discussed these issues highlighting that most teachers focus almost exclusively on teaching how to solve the specific mathematics most likely to be found in the national examination. Therefore, their approach doesn't even attempt to foster true understanding of the Mathematics concepts and the development of thinking. Most teachers used exposition in Mathematics instruction, and spent time only 32\% on problem solving. Thus teachers talk more than students, and almost all of the tests use routine problems that are not challenging for students. Most of the teachers depend on the textbook, and do not have the skills to make interesting activities, good questions or challenging tests.

Enhancing the ability of the students in mathematical problem solving and making mathematical connections can be supported by using technology such a dynamic software as a tool to help students link the concrete and the symbolic of mathematics. One of the commercial dynamic software programs introduced in mathematics classroom is Autograph ${ }^{\mathrm{TM}}$. It has features to help students solve problems in statistics. The “drag” and various "zoom" options can be used to get a clearer picture for students to visualise their statistical results. The free interaction of students with the computer provides more opportunities to do exploration and investigation in developing their thinking. 


\section{Integrating Technology in Mathematics Learning}

Technology becomes a more prevalent part of western education culture with each passing year. Schools cannot ignore the impact of technology and the changing face of curriculum. The calculators, computer, and other technologies are potentially important tools for generating discussions in the mathematics classroom. The Principles and Standards for School Mathematics in the USA states that "technology is essential in teaching and learning mathematics, it influences the mathematics that is taught and enhances students learning" (NCTM, 1989, p. 24).

Wright (Alexiou-Ray, Wilson, Wright \& Peirano, 2003) reports higher student achievement, self-concept, attitude and teacher-student interaction as a result of interactive learning made possible via the use of technology. Kerrigan (Alexiou-Ray, et.al., 2003) also reported the benefits of using mathematics software and websites to promote students' highorder thinking skills, while developing and maintaining their computational skills, introducing them to collection and analysis data, facilitating their algebraic and geometric thinking, and showing them the role of mathematics in an interdisciplinary setting.

Resnick (2001) stated that teachers should understand that new technology changes not only what students should learn, but also what they can learn. This means that concepts and ideas that might have been inaccessible can now be experienced and understood in the context of learning with information and communication technology. Technology not only influences how mathematics is taught and learned but also affects what is taught and where a topic now appears in the curriculum.

\section{Introducing A Dynamic Software Program}

Dynamic software is often employed as a fertile learning environment in which students can be actively engaged in constructing and exploring mathematical ideas (Cuoco \& Goldenberg, 1996). Autograph ${ }^{\mathrm{TM}}$ is a Dynamic Software program for teaching mathematics such as calculus, algebra and coordinate geometry. It was developed by Douglas Butler (2005), and was designed to help students and teachers visualize mathematics at secondary/college level, using dynamically linked 'objects'. Autograph ${ }^{\mathrm{TM}}$ highlights the use of dependent, selectable mathematics objects to help student get to grips with the principles of probability and statistics, coordinate geometry, in both 2D and 3D. Autograph ${ }^{\mathrm{TM}}$ provides 
facility to sketch curves (both implicitly and explicitly defined) solve simultaneous equations, plot derivatives, etc. It operates in 3 modes: 1D for Statistics \& Probability; 2D for Graphing, Coordinates, Transformations and Bi-variates Data and 3D for Graphing, Coordinates and Transformation in three dimensions.
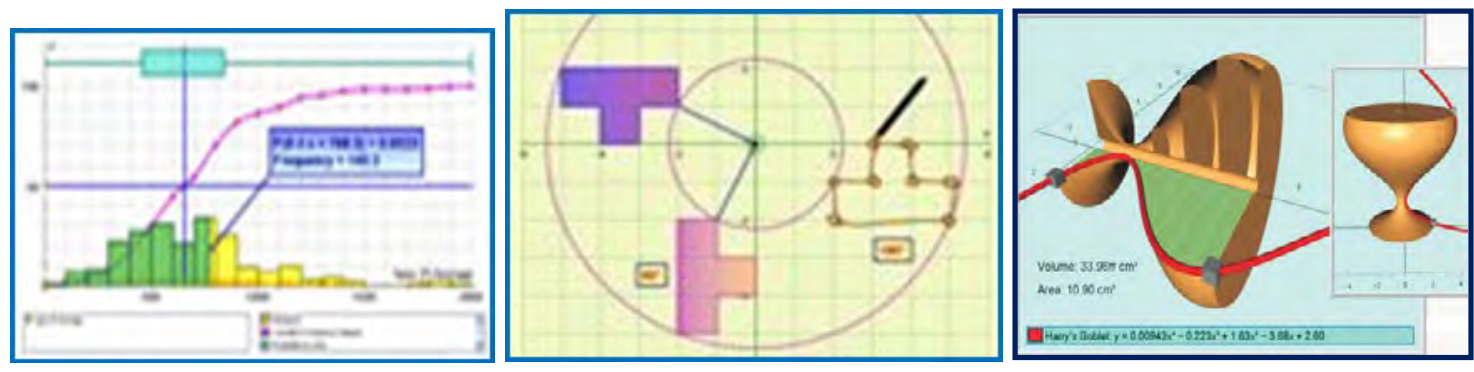

Figure 1: Three modes: 1D statistics, 2D Geometry, and 3D Algebra

Autograph ${ }^{\mathrm{TM}}$ has two levels of operation; 'standard' and 'advanced' operation. The 'standard' level has a greatly simplified interface and reduced set options for the user. At the 'Advanced' level, more challenging problems and investigations can be explored. Autograph ${ }^{\mathrm{TM}}$ brings mathematics to life, whether through true-to-form animations or through student-driven exploration. The powerful features and point-and-click technology will engage all levels of students. By using this technology, users can observe how functions, graphs, equations, and calculations work. It also enables users to change and animate graphs, shapes, and vectors already plotted to encourage understanding of concepts. In the mathematics classroom the use of mathematical software enables students to visualize and further understand mathematical phenomenon in real life.

The interactive features of Autograph ${ }^{\mathrm{TM}}$ allow students to become engaged in the mathematics through teacher-led lessons or in explorations where the answers are found by the students themselves. The introduction of the computer into the school classroom has brought a new technique to teaching, the technique of simulation. In the context of teaching statistics, computer simulation enables students to generate data having the essential characteristic of variability and to follow processes run at a convenient speed which may be faster or slower than in the real instance. The student can now be placed in a decision-making role, a role in which he has to make statistical inferences based on data presented to him and then to take the appropriate actions. It is an essential feature of the interactive simulation that the next set of data generated and presented will depend on the student's previous decisions. Teaching by integrating Autograph ${ }^{\mathrm{TM}}$ in schools might increase the effectiveness and the 
quality of teaching. Autograph "is an extremely useful educational tool for both mathematics teachers and students which help teachers to present the content for the whole class easily and students understand better due to its visual demonstration” (Tarmidzi, Ayub, Abubakar \& Yunus, 2008, p. 186).

\section{Mathematical Problem Solving and Mathematical Connection}

\section{Mathematical Problem Solving}

Problem solving is an integral part of all mathematics learning. In everyday life and in the workplace, being able to solve problems can lead to great advantages. However, problem solving is not only a goal of learning mathematics it is also a means of doing so. The National Council of Mathematics Teachers (NCTM) emphasizes that problem solving has a special importance in the study of mathematics. Furthermore, it states that problem solving should underlie all aspects of mathematics teaching in order to give students experience of the power of mathematics in the world around them. The council sees problem solving as a vehicle for students to construct, evaluate and refine their own theories about mathematics and the theories of others. Unfortunately, from of all of the reform recommendations being made by the NCTM, making mathematical connections is among the more difficult to achieve, yet is so helpful in motivating students in the early grades. Mathematical connections can relate mathematical topics to students' daily lives and to other mathematical topics but are probably most important in relating mathematics to other curriculum areas. The NCTM standards stated two general types of connections, that is modelling connections between problem situations that may arise in the real world or in disciplines other than mathematics and their mathematical representations; and mathematical connections between two equivalent representations and between corresponding processes in each. Many countries emphasize the role of modelling and applications in mathematics education. It became a major objective that students should be able to apply mathematical problem-solving and reasoning skills and attitudes in real-life and scientific situations. It may be concluded that there is a strong relation between mathematical connection and the ability of the student to solving a problem.

Problem solving is one component of higher level thinking. To think effectively, students also need to develop their meta-cognitive skills of planning, monitoring and evaluating so they can plan, monitor and evaluate their academic work. Cooperative learning is an especially effective method of spontaneously activating meta-cognitive aspects of thinking, learning and problem solving. 
Studies comparing cooperative learning with competitive and individualistic learning demonstrated that cooperative learning promotes higher achievement than the other two methods. Not only do students solve problems more successfully and learn and retain concepts, but cooperative learning also results in more use of higher level thinking, more frequent discovery, generating new ideas and solution strategies, and more transfer of what is learned about problem solving in groups to individual problem solving situations (Johnson, Johnson \& Holubec, 1994). These benefits are a result of students internalizing concepts and problem solving through their discussions and explanations of problem solving strategies and approaches with their peers. Giving explanations to other students requires deeper understanding than just putting an answer on a worksheet. Finally, many research studies found that cooperative group instruction shows significantly better results in mathematics achievement and problem solving skills.

Many studies in the field of educational technology have demonstrated how the personal computer assisted cooperative learning provides better results than traditional learning in a competitive, individualist setting. Personal computers are especially suited, among other roles, to that of initiating and sustaining cooperative and collaborative learning. Recent curriculum reforms suggest that students need to utilize distinct technological tools in their process of learning mathematics.

In this study, mathematical problem solving is defined as the ability of the students to use problem solving approaches to investigate and understand mathematical content, apply integrated mathematical problem-solving strategies to solve problems from within and outside mathematics, recognize and formulate problems from situations within and outside mathematics, and to apply the process of mathematical modelling to real world problem situation. All of this can be summarised in the following steps: (1) understanding the problem; (2) devising a plan for finding a solution; (3) implementing the plan; and (4) looking back at the answer.

\section{Mathematical Connection}

Making mathematical connections refers to the ability of the student to: (1) recognize equivalent representations of the same topics, (2) relate procedures in one representation to procedures in an equivalent representation, and (3) use and appreciate the connections between mathematics and other disciplines. The cooperative learning with the Think-Pair Share method can be described with the activity of 2 students with one problem where they share their ideas or questions, each person speaks, listens and gives feedback, and then the students will assess individually. 


\section{Cooperative Learning Think-Pair-Share}

Cooperative learning Think-Pair-Share (TPS) was originally developed by Lyman (1981). Think-Pair-Share allows for students to contemplate a posed question or problem silently. The think-pair-share strategy is a cooperative learning technique that encourages individual participation and is applicable across all grade levels and class sizes. Students think through questions using three distinct steps: (1) Students think independently about the question that has been posed, forming ideas of their own and then may write some thoughts in response to the question.; (2) Students are grouped in pairs to discuss their thoughts and changing their ideas with others; (3) Students share their ideas with a larger group, such as the whole class to refine their ideas.

Some studies showed that students need many opportunities to talk in a linguistically rich environment. Researchers have found that students' learning is enhanced when they have many opportunities to elaborate on ideas through talk (Pressley 1992). The TPS strategy increases the kinds of personal communications that are necessary for students to internally process, organize, and retain ideas (Pimm, 1987). In sharing their ideas, students take ownership of their learning and negotiate meanings rather than rely solely on the teacher's authority (Cobb et al., 1991). Additional benefits of using the TPS strategy include: (1) the positive changes in students' self-esteem that occur when they listen to one another and respect others' ideas; (2) the opportunity to learn higher-level thinking skills from their peers, gain the extra time or prompting they may need; and (3) the gaining of confidence when reporting ideas to the whole class. The TPS strategy can be used in a variety of contexts. However, to be effective, students must consider a question or issue and they should derive some benefit from thinking about it further with partners, such as when there are multiple correct answers to a question.

\section{Methodology}

The purpose of this study was to investigate: (1) whether the implementation of the use of the dynamic software program Autograph ${ }^{\mathrm{TM}}$ in cooperative learning type think-pairshare context could enhance students' mathematical problem solving and mathematical connections; (2) the level of enhancement in students' mathematical problem solving and mathematical connections; (3) the student activity during the implementation; and (4) student perceptions toward the implementation. 
The target population of the study was 188 students of Grade XI in 4 classes in a Senior High School, Medan Indonesia. The sample of this study was determined with random sampling technique, with the name of the class as object of the drawing, selecting one from four. One class of 34 students was selected as a sample in this study and consisted of $27 \%$ high, 50\% medium and 23\% low students. The students in the study were taught and learned statistics and probability using TPS and Autograph ${ }^{\mathrm{TM}}$.

The design of this study was one group-within treatment design. A within-subjects design is an experiment in which the same group of subjects serves in more than one treatment. Three treatments were conducted to the students. Students were tested after 2, 4 and 6 treatments.

In this study, each student was provided with one computer installed with Autograph $^{\mathrm{TM}}$ software. In the first phase, the students were required to explore and be familiar with the software and its functions in learning statistics. In the second phase, students were introduced to the basic concepts of a Statistics topic with the teaching and learning using the software. This phase involved instruction using the constructivist approach where students actively explore and discover concept of statistics using modular activity using TPS approach.

The instructional materials for this study consisted of four sets of 2-hour lesson plans for teaching and learning of Statistics. The lesson plans were developed based on the following topics: introduction to statistics, measure of central tendency: mean, median, mode, bar graph, line graph and circular graph. Modules were developed to enable the students to learn statistics using cooperative learning TPS and dynamic software with a variety of contexts in learning statistics.

Before the study, the instruments were pilot tested to obtain the reliability, validity and the difficulty level of the test. These instruments then were administered by giving the pretest and the treatments for 8 meetings. Prior to the data collection, the students were taught how to launch and use Autograph ${ }^{\mathrm{TM}}$ in learning statistics. At the end of the treatment, a post test was administered and then the data was analysed.

Before testing the hypotheses, the normality of the data of all the tests (mathematical problem solving and mathematical connection) was tested using chi-square test. After data analysis, it was found that all of the data were normally distributed. Testing the homogeneity of variance from the score of the pre-test and the post-test by using F-Test, it was found that the data were homogenous. Finally, ANOVA test was conducted to investigate the effect of 
using Autograph ${ }^{\mathrm{TM}}$ in enhancing the students' ability in mathematical problem solving and mathematical connections.

Two kinds of instruments were applied in this study, test and questionnaire. The test was used to measure the student's ability on the mathematical problem solving and mathematical connections. The questionnaire was used to find out students' perceptions on learning using dynamic software. The indicators of mathematical problem solving included: using problem solving approaches to investigate and understand mathematical content; applying integrated mathematical problem solving strategies to solve problem from within and outside mathematics; recognizing and formulating problems from situations within and outside mathematics; and applying the process of mathematical modelling to real world problem situation. The indicators of mathematical connection were: recognizing equivalent representations of the same topics; relating procedures in one representation to procedures in an equivalent representation; and using and appreciating the connections between mathematics and other disciplines. In evaluating the ability of mathematical problem solving and mathematical connections from the sample, analytic scoring rubrics were used in which the components of mathematical problem solving and mathematical connections were defined and scored separately based on the scoring purposes of these variables.

The questionnaire was a five-point Likert Scale used to investigate students' perception on the use of dynamic software. The observation sheets were used to know the student's activity during the learning process in using dynamic software in cooperative learning. The observations were conducted to observe the teaching learning process in the classroom and math lab. Three mathematics teachers acted as the observers.

\section{Pre-test}

\section{Results}

The result of the pre-test was used to establish the students' prior ability with the purpose to group students into high and low ability groups. The results of the pre-test of the groups are shown in Table below.

Table 1

Pre-test score of Math Problem Solving and Math Connection

\begin{tabular}{ccccccc}
\hline Pre-test & Group & N & Min & Max & Mean & Sd \\
\hline \multirow{3}{*}{ PM } & 1 (upper) & 17 & 75 & 84 & 80.94 & 3.07 \\
& 2 (lower) & 17 & 55 & 77 & 66.12 & 6.65 \\
\cline { 2 - 7 } & Total & 34 & 55 & 84 & 74.00 & 9.19 \\
\hline \multirow{3}{*}{ KM } & 1 (upper) & 17 & 92 & 76 & 80.0 & 5.35 \\
& 2 (lower) & 17 & 42 & 75 & 62.24 & 9.46 \\
\cline { 2 - 7 } & Total & 34 & 42 & 92 & 66.00 & 10.81 \\
\hline
\end{tabular}


The results show that the average scores and standard deviation of the pre-tests on math problem solving and math connection are 74 (9.19) and 66 (10.81) with the lowest scores 55 and the highest 84 for math problem solving, and the lowest score of 42 and the highest score 92 for math connection.

\section{Scores After Treatment}

The results of analysis of the data on the second, the fourth and the sixth instructions on mathematical problem solving and mathematical connection are shown in Table 2 below.

Table 2

Pre-test score of Math Problem Solving and Math Connection

\begin{tabular}{clccccc}
\hline Instruction & Group & \multicolumn{2}{c}{ Math Problem Solving } & \multicolumn{2}{c}{ Math Connection } & \\
& & Mean & Sd & Mean & Sd & N \\
\hline \multirow{2}{*}{2 times } & Upper & 82 & 3.25 & 76 & 10.16 & 17 \\
& Lower & 70 & 6.64 & 65 & 5.54 & 17 \\
\cline { 2 - 7 } & Total & 76 & 7.82 & 70 & 9.88 & 34 \\
\hline \multirow{5}{*}{4 times } & Upper & 84 & 5.09 & 78 & 9.75 & 17 \\
& Lower & 75 & 6.95 & 69 & 7.07 & 17 \\
\cline { 2 - 7 } 6 times & Total & 80 & 7.47 & 74 & 9.51 & 34 \\
\hline \multirow{5}{*}{ Upper } & 86 & 4.22 & 80 & 7.25 & 17 \\
& Lower & 79 & 6.54 & 75 & 6.89 & 17 \\
\cline { 2 - 7 } & Total & 82 & 5.73 & 78 & 7.32 & 34
\end{tabular}

\section{Mathematical Problem Solving}

Results of data analysis on student's problem solving ability in Table 2 shows that the average score of the upper level and the lower level students are increased. After 2, 4, and 6 times instructions the average scores on problem solving ability were increased from 82 to 84 and to 86 for upper level, while the average score on problem solving ability of students at the lower level are also increased from 70 to 75 and 79 on the 2nd, 4th, and 6th instruction.

Hypotheses testing using parametric t-test to test the differences between the average scores on mathematical problem solving ability after 2, 4, 6 times of instructions with level of significant $\alpha=0,05$ (two-tail test). The results showed that the use of Autograph ${ }^{\mathrm{TM}} \mathrm{kept}$ increasing the students' math problem solving ability after 2, 4, and 6 times of instructions.

\section{Mathematical Connection}

Results of data analysis on student's mathematical connection in Table 2 shows that average score for the upper level and lower level students are increased. After 2, 4, and 6 times instructions the average scores was increased from 76, to 78, and to 80 for upper level, 
while the average score of students at the lower level are also increased from 65 to 69 and 75 on the 2nd, 4th, and 6th instruction. Hypotheses testing using parametric t-test to test the differences between the average scores on mathematical connection ability after 2, 4, 6 times of instructions with level of significant $\alpha=0,05$ (two-tail test). The results showed that the use of Autograph ${ }^{\mathrm{TM}}$ keep increasing the students' mathematical connection.

\section{Student Perceptions}

The students' perception on the use of the dynamic software related to the students' ability in Mathematical Problem Solving and Mathematical Connection indicated that most of the students answered Strongly Agree (SS) and Agree (S) for positive questions and answered Disagree (TS) and Strongly Disagree (STS) for the negative constructed questions. The summary of the results were: (1) most of the students (88.62\%) like to study mathematics; (2) most of the students (85\%) want to learn mathematics seriously; (3) most of the students (88\%) like the cooperative learning type Think-Pair-Share; (4) most of the students (93.21\%) argued that the cooperative learning type Think-Pair-Share was useful in the mathematics learning; (5) most of the students like working with the Student's Worksheets and the manual book of Autograph ${ }^{\mathrm{TM}}$; (6) most of the students like the dynamic software Autograph ${ }^{\mathrm{TM}}$; (7) all of the students like to use the dynamic software in learning mathematics.

\section{Discussion}

The data collected from this study was analysed to obtain answers to the research questions. The data included the score of the students in the tests, the observations and questionnaire results. From the results of all the tests, it can be concluded that the mean of students' mathematical problem solving in the treatment 1 where the implementation of dynamic software just for board presentation by the teacher was not significantly different from the mean of students' mathematical problem solving in treatment 2 where the implementation of the dynamic software was just used when the students worked in the Think-Pair-Share setting. The significant difference occurred when the implementation of the dynamic software was involved all of time during mathematical learning from treatment 1 to treatment 2 and treatment 3. These results and conclusions were also similar for students' mathematical connections.

The effect of Treatment 3 showed in the students' mastery. Before using the dynamic software the students' mastery above the MCC (Minimum Competency Criteria) was only $44 \%$ or 13 among the 34 of students, and most of the students who passed the MCC were in 
the 'adequate' level. After treatment 3 learning by using the dynamic software at all of times during the learning process, the students who passed the MCC had increased to 85,2 \%, and most of the students were in the 'good' level. The enhancement in student mastery was about $41.2 \%$.

From the analysis of the observation sheets, it was concluded that the students were mostly actively engaged during the mathematical learning with dynamic software (3.995 in scale of 5 or $79.95 \%$ in percentage). The lowest percentage was shown when the students were asked to formulate thoughts and ideas and in writing their ideas necessary to prepare for sharing with a partner was 73\%. The highest percentage (88\%) occurred when the students were reading the Student's Worksheets in the core activity. During the introduction, the highest percentage (87\%) was shown when the students listened to the aim of the subject of learning. The activity when the students listened to the motivation given by the teacher and answered the teacher's questions had the same percentage of $78 \%$. In the core activity, the lowest percentage was also the lowest percentage for these observations when the students were formulating their thoughts and ideas, writing down ideas to prepare for sharing with their partners. In the closing section, participation in making a summary and conclusion was $87 \%$ and listening to the brief explanation for further subject was $75 \%$.

\section{Conclusion}

Based upon the findings derived from the data analysis of the investigation, it was concluded that: (1) the cooperative learning type Think-Pair-Share with the use of the dynamic software enhanced the students' Mathematical Problem Solving and Mathematical Connections; (2) the enhancements of the students' mathematical problem solving and mathematical connections were shown in the students' mastery and the students' activity during learning processes; (3) the use of dynamics software and TPS lead to the students being more active and doing activities at a better level; and (4) the students reported a good perception towards the approach.

Due to the size of the sample, it is only possible to make suggestions. It is suggested that: (1) teachers can apply this learning model as an alternative in mathematics learning; (2) the dynamic software Autograph ${ }^{\mathrm{TM}}$ can be used in mathematics instruction as a tool to help student learning and may assist the teacher to provide more an active and enjoyable mathematics classroom environment. To examine the sustainability of the results reported in this study, further studies need to be conducted with other populations and with different mathematics topics. 


\section{References}

Alexiou-Ray, J.A., Wilson, E., Wright, V.H., Peirano, A.M.(2009), Changing Instructional Practice: The Impact of Technology Integration on Students, Parents, and School Personnel. Retrieved May 12, 2009 from: http://ejite.isu.edu/Volume2No2/AlexRay.htm

Butler, D., \& Hatsel, M. (2007). Autograph 3. Getting Going with Autograph 3. UK: Eastmond Publishing Ltd.

Cobb, P., Wood, T., \& Yackel, E. (1991). 'A constructivist approach to second grade mathematics'. In E. von Glaserfield (Ed.), Radical Constructivism in Mathematics Education, (pp. 157-176). Dordrecht, The Netherlands: Kluwer Academic Publishers.

Cuoco, A., Goldenberg, E.P., \& Mark, J. (1996). Habits of Mind: an organizing principal for a mathematics curriculum. Journal of Mathematical Behaviour, 15(4), 375-402.

Johnson, D.W., Johnson, R.T. \& Holubec, E.J. 1994. Cooperative Learning in the Classroom. VA: Association for Supervision and Curriculum Development.

Kurz, T. L., Middleton, J. A., \& Yanik, H. B. (2005). A taxonomy of software for mathematics instruction. Contemporary Issues in Technology and Teacher Education. [Online serial], 5(2). Retrieved March 21, 2009. From: http://www.citejournal.org/vol5/iss2/mathematics/article1.cfm.

Lyman, F.T. (1981). The responsive classroom discussion: The inclusion of all students. In A. Anderson (Ed), Mainstreaming Digest (pp. 109-113). College Park: University of Maryland Press.

Martin, H. 2006. Making Math Connection: Using Real World Application with Middle School Students. NY: Corwin Press.

National Council of Teachers of Mathematics. (1989). Curriculum and Evaluation Standard for School Mathematics. Reston, VA : NCTM.

National Council of Teachers of Mathematics. (1991). Professional Standards for Teaching Mathematics. Reston, VA : NCTM.

Pimm, D. (1987). Speaking mathematically: Communication in mathematics classrooms. London: Routledge Kegan \& Paul.

Pressley, M., Wood, E., Woloshyn,V. E., Martin, V., King, A., \& Menke, D. (1992). Encouraging mindful use of prior knowledge: Attempting to construct explanatory answers facilitates learning. Educational Psychologist, 27(1), 91-109.

Resnick, L.B., \& Ford, W. W. (1981). Psychology of Mathematics for Instruction. Hillsdale, NJ. Lawrence Erlbaum.

Tarmidzi, R. A., Mohd. Ayub, A. F., Abu Bakar, K., \& Md. Yunus, A. S. (2008). Instructional Efficiency Of Utilization Of Autograph Technology Vs Handheld Graphing Calculator In Learning Algebra. International Journal of Education And Information Technologies. 3(2), 184-193. 